\title{
Postpartum fever in the presence of a fibroid: Sphingomonas paucimobilis sepsis associated with pyomyoma
}

\author{
Cosmo Del Borgo ${ }^{1}$, Francesco Maneschi ${ }^{2}$, Valeria Belvisi ${ }^{1}$, Francesca Morelli ${ }^{1}$, Angelo Vetica ${ }^{1}$, Raffaella Marocco ${ }^{1}$, \\ Tiziana Tieghi ${ }^{1}$, Miriam Lichtner ${ }^{1}$ and Claudio M Mastroianni ${ }^{\text {* }}$
}

\begin{abstract}
Background: Pyomyoma is a life-threatening complication of uterine leiomyoma. It may occur in post- menopausal women, during pregnancy and in the postpartum period. Fever may be the only manifestation during the early stages of the disease. We detail the first reported case of postpartum pyomyoma-related sepsis due to Sphingomonas paucimobilis, a Gram-negative bacillus that is gaining recognition as an important human pathogen.

Case presentation: A woman presented with an asymptomatic uterine fibroid and a two-week history of fever during the postpartum period. Suppurative uterine leiomyoma was diagnosed, and blood cultures grew Sphingomonas paucimobilis. The myoma was surgically removed from the uterus without hysterectomy. Intravenous antimicrobial therapy was given for fifteen days, and the patient was discharged from hospital in good condition.

Conclusion: Pyomyoma should be considered in broad differential diagnosis of postpartum fever. This case highlights a unique disease manifestation of S. paucimobilis, an emerging opportunistic pathogen with increasing significance in the nosocomial setting.
\end{abstract}

Keywords: Pyomyoma, Fever, Sphingomonas paucimobilis septicaemia

\section{Background}

Pyomyoma is a life-threatening complication of uterine leiomyoma [1]. This suppurative process is rare, especially in the postpartum period, in which it can develop insidiously. It can cause abdominal pain, but fever is generally the only symptom, especially in the early stages. As it is fatal without surgical treatment [2], thorough investigation of patients presenting with fever and leiomyoma is crucial, bearing in mind that radiological findings are often nonspecific.

Pyomyoma is usually associated with polymicrobial infection with microorganisms such as Clostridium sp, Staphyloccocus sp, and Enterobacteriaceae. Here, however, we report the case of a woman who, during the puerperal period, developed pyomyoma ascribed to Sphingomonas paucimobilis bacteraemia.

\footnotetext{
* Correspondence: claudio.mastroianni@uniroma1.it

${ }^{1}$ Infectious Disease Unit, Fondazione Eleonora Lorillard Spencer Cenci,

Sapienza University, Corso Della Repubblica 79, 04100 Latina, Italy

Full list of author information is available at the end of the article
}

Sphingomonas paucimobilis is a yellow-pigmented, aerobic, non-fermenting, Gram-negative bacillus that thrives in a variety of natural environments such as soil and water $[3,4]$. It has also been detected in ultrapure water in industrial systems, and is able to form biofilms in water piping. Outbreaks associated with indwelling devices and contaminated fluid preparations have been described, and S. paucimobilis bacteraemia in various clinical settings has been reported with increasing frequency [5-8].

\section{Case presentation}

In September 2012, a 37-year-old woman was hospitalized due to a two-week history of persistent fever. Thirty days before she had given birth to a healthy child through normal vaginal delivery in the $39^{\text {th }}$ week. The patient had a history of asymptomatic uterine fibroid, but no systematic follow-up had been performed, despite two first-trimester abortions in the two years prior to hospitalization. She had had no recent history of

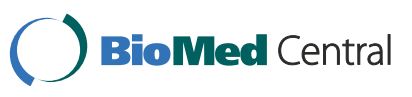


antibiotic treatment, and her records showed no previous invasive procedures, instrumentation or foreign bodies in the uterus.

On admission, body temperature was $39^{\circ} \mathrm{C}$, blood pressure $105 / 50 \mathrm{mmHg}$, and pulse 100 beats/min. Her respiratory rate was 30 breaths/min. Physical findings were normal, except for tenderness in lower abdominal quadrants. Gynaecological examination revealed an enlarged uterus with tenderness upon deep palpation. Laboratory tests revealed a white blood cell count of $14,200 / \mathrm{mm}^{3}$ (81.5\% neutrophils) and platelet count of $95,000 / \mathrm{mm}^{3}$. C-reactive protein and procalcitonin were $10.8 \mathrm{mg} / \mathrm{dL}$ and $59.71 \mathrm{ng} / \mathrm{mL}$, respectively. Chest X-ray was negative for pleuroparenchymal lesions, and transthoracic echocardiogram was negative for valvular vegetations. Abdominal ultrasound revealed hepatosplenomegaly, but was negative for effusion and nodular lesions.

Since no evident source of infection was apparent, a full-body CT scan was performed. Images showed mild bilateral hydroureteronephrosis and an enlarged uterus with heterogeneous masses suggestive of leiomyoma (Figure 1).

The patient was accordingly started on meropenem and amikacin, but after a three-day course, her temperature remained high $\left(39^{\circ} \mathrm{C}\right)$ and her clinical conditions failed to improve. Antibiotic treatment was therefore supplemented with teicoplanin and metronidazole.

Blood cultures grew S. paucimobilis, which was fully responsive to all tested antibiotics including $\beta$-lactams, carbapenems, and fluoroquinolones (Table 1).

A new CT scan documented a thickening of the pulmonary interstitium, bilateral basal pleural effusion, and slight effusion in the rectouterine pouch and pelvis. Transvaginal ultrasound confirmed uterine enlargement, and revealed two hypointense solid masses located over the fundal portion and left side of the uterine body.

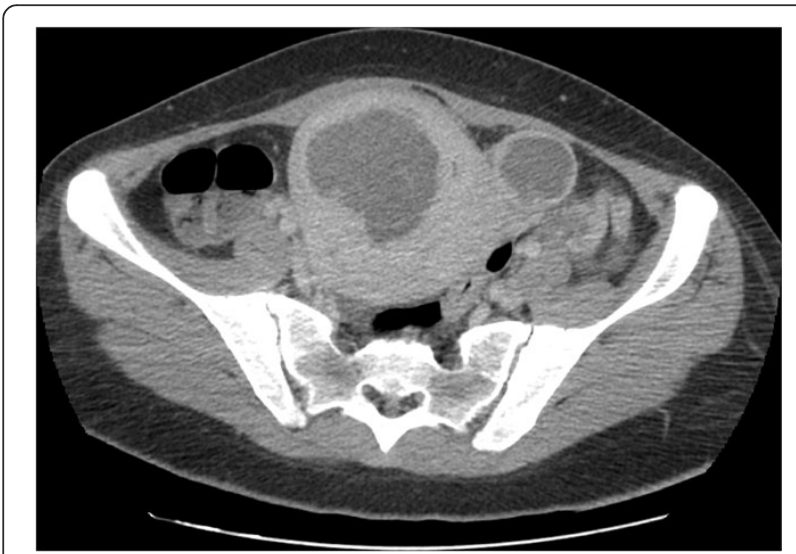

Figure $1 \mathrm{CT}$ scan, abdominal view: mild bilateral hydroureteronephrosis and enlarged uterus with heterogeneous masses.
Table 1 Antimicrobial drug susceptibility of Sphingomonas paucimobilis

\begin{tabular}{lcc}
\hline Antimicrobial drug & Susceptibility & MIC $(\boldsymbol{\mu g} / \mathbf{m l})$ \\
\hline Ampicillin & $\mathrm{S}$ & $<=2$ \\
Cefotaxime & $\mathrm{S}$ & $<=1$ \\
Gentamicin & $\mathrm{S}$ & $<=1$ \\
Amikacin & $\mathrm{S}$ & $<=2$ \\
Levofloxacin & $\mathrm{S}$ & $<=0.12$ \\
Meropenem & $\mathrm{S}$ & $<=0.25$ \\
Cefepime & $\mathrm{S}$ & $<=1$ \\
Tygeciclin & $\mathrm{S}$ & $<=0.5$ \\
\hline
\end{tabular}

S, susceptible. MICs are based on EUCAST breakpoints.

Explorative laparotomy revealed a large myoma $(10 \mathrm{~cm})$ located over the fundus of the enlarged uterus, and a smaller myoma $(3 \mathrm{~cm})$ on the left side of the uterine body. A small amount of ascitic fluid was also present in the rectouterine pouch. The fundal myoma was dissected from the uterus, resulting in an outflow of purulent fluid and colliquative necrotic material (Figure 2). Hysterectomy was not deemed necessary, and no complications arose during the postoperative course.

Antibiotic therapy with teicoplanin, metronidazole and meropenem was given for fifteen days, and histopathology confirmed the diagnosis of pyomyoma. Aerobic and anaerobic cultures obtained from the specimen did not yield bacterial growth. The patient was discharged from hospital in good condition on postoperative day 16 .

\section{Conclusions}

Pyomyoma (also known as suppurative leiomyoma) is a rare but life-threatening condition resulting from infarction and infection of uterine leiomyoma [1,2]. Predisposing risk factors include gynaecological surgery, uterine instrumentation, vascular insufficiency, and immunodeficiency. Pyomyoma may occur in both post-menopausal and pre-menopausal women, but the risk of suppurative complications of myoma is increased by pregnancy.

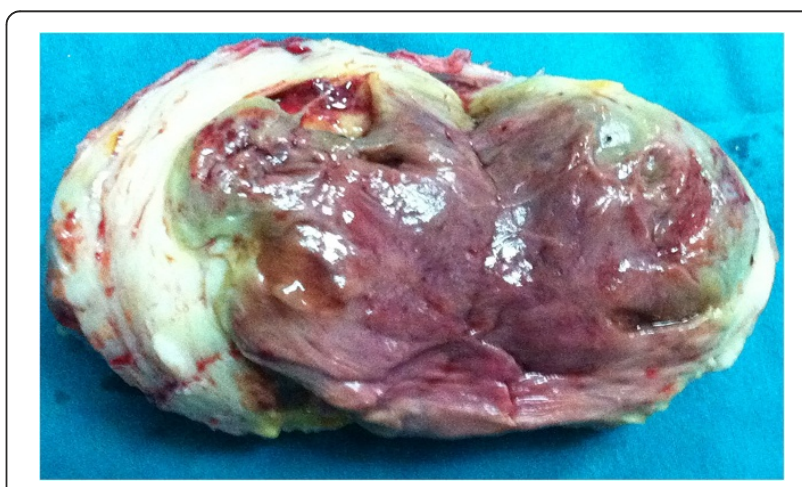

Figure 2 Surgical specimen: anterior view of $10 \mathrm{~cm}$ dissected pyomioma of uterine fundus. 
Nonetheless, since 1945, only 17 pyomyoma cases (including our patient) arising during pregnancy or the postpartum period have been reported (Table 2). The previous case reports indicate that infection may arise as consequence of abortion, caesarean section or intravenous drug abuse, and most infections recorded in the postpartum period developed insidiously over days to weeks between delivery and onset of symptoms.

Abdominal pain was reported in some cases, but fever was generally the only symptom, especially in the early stages. Hence, attending physicians need to be particularly vigilant in cases of postpartum fever and leiomyoma, as neither radiology nor pelvic ultrasound are likely to be diagnostic. Indeed, although pyomyoma has been associated with poor obstetric outcomes, prompt surgical intervention can improve clinical results [2].

In post-menopausal women and patients with small multiple intramural lesions or ruptured myomas, total abdominal hysterectomy is the preferred option. Nevertheless, a more conservative approach based on myomectomy or computed tomography-guided drainage of pyomyoma is now feasible [19], and indeed preferable in

Table 2 Pyomyoma during pregnancy or in postpartum period

\begin{tabular}{|c|c|c|c|c|c|}
\hline Author and year & Onset of symptoms & Underlying condition & Surgical intervention & Pathogen & Outcome \\
\hline Dubois [9] & 3 weeks postpartum & - & vaginal expulsion of pyomyoma & N/A & N/A \\
\hline Ruch [10] & $\begin{array}{l}5 \text { month pregnancy/ } \\
1 \text { day postpartum }\end{array}$ & - & $\begin{array}{c}\text { total abdominal hysterectomy }+ \\
\text { appendectomy }\end{array}$ & Gram positive cocci & N/A \\
\hline Wong [11] & 3 days post-abortion & $\begin{array}{l}18 \text { weeks IUD associated } \\
\text { spontaneous abortion }\end{array}$ & $\begin{array}{c}\text { total abdominal hysterectomy + } \\
\text { left salpingectomy }\end{array}$ & $\begin{array}{c}\text { Staphylococcus aureus + } \\
\text { Serratia marcescens }\end{array}$ & N/A \\
\hline Prichard [12] & $\begin{array}{c}9 \text { weeks post-abortion } \\
\text { (spontaneous) }\end{array}$ & - & $\begin{array}{c}\text { total abdominal hysterectomy }+ \\
\text { bilateral salpingectomy }\end{array}$ & Streptococcus milleri & N/A \\
\hline Tobias [13] & 10 weeks post-abortion & $\begin{array}{l}\text { uterine fibroids, } 15 \text { weeks } \\
\text { elective abortion }\end{array}$ & $\begin{array}{c}\text { total abdominal hysterectomy }+ \\
\text { bilateral salpingectomy }\end{array}$ & Enterococcus faecalis & S \\
\hline Prahlow [14] & 12 weeks pregnancy & intravenous drug abuse & $\begin{array}{c}\text { total abdominal hysterectomy }+ \\
\text { bilateral salpingectomy }+ \\
\text { partial omentectomy }\end{array}$ & Staphylococcus aureus & N/A \\
\hline Grüne [15] & 25 weeks pregnancy & - & cesarean section + myomectomy & Klebsiella pneumoniae & S \\
\hline Lin [16] & 6 days postpartum & $\begin{array}{l}\text { uterine fibroids, preterm } \\
\text { premature rupture of } \\
\text { membranes, surgical site } \\
\text { infection (cesarean section) }\end{array}$ & total abdominal hysterectomy & $\begin{array}{l}\text { Escherichia coli }+ \\
\text { Candida parapsilosis }\end{array}$ & S \\
\hline Karcaaltincaba [17] & $\begin{array}{l}7 \text { days post-abortion } \\
\text { (spontaneous) }\end{array}$ & - & myomectomy & Peptostreptococcus tetradus & S \\
\hline Mason [1] & 21 days postpartum & $\begin{array}{c}\text { manual removal of adherent } \\
\text { placenta after full term } \\
\text { vaginal delivery }\end{array}$ & myomectomy & no growth & S \\
\hline Nguyen [18] & 3 weeks postpartum & $\begin{array}{l}41 \text { weeks cesarean section } \\
\text { delivery, severe } \\
\text { chorioamnionitis }\end{array}$ & total abdominal hysterectomy & Escherichia coli & S \\
\hline Laubach [19] & $\begin{array}{l}18 \text { hours post- abortion } \\
\text { (spontaneous) }\end{array}$ & - & $\begin{array}{c}\text { vaginal expulsion of } \\
\text { pyomyoma + computed } \\
\text { tomography- uided drainage }\end{array}$ & Escherichia coli & S \\
\hline Laubach [19] & postpartum period & $\begin{array}{l}33 \text { weeks cesarean section } \\
\text { delivery, preterm premature } \\
\text { rupture of membranes, } \\
\text { chorioamnionitis }\end{array}$ & $\begin{array}{l}\text { computed tomography-guided } \\
\text { drainage }\end{array}$ & $\begin{array}{l}\text { Escherichia colit } \\
\text { Candida albicans }+ \\
\text { Candida dubliniensis }\end{array}$ & S \\
\hline Laubach [19] & N/A & $\begin{array}{l}29 \text { weeks cesarean section } \\
\text { delivery, preterm premature } \\
\text { rupture of membranes, } \\
\text { surgical site infection }\end{array}$ & $\begin{array}{c}\text { computed tomography-guided } \\
\text { drainage + subtotal abdominal } \\
\text { hysterectomy }\end{array}$ & $\begin{array}{l}\text { Enterococcus faecalis + } \\
\text { Streptococcus spp. }\end{array}$ & S \\
\hline Shaaban [20] & 8 weeks postpartum & cesarean section & myomectomy & $\begin{array}{l}\text { Staphylococcus } \\
\text { lugdunensis }\end{array}$ & $S$ \\
\hline Kobayashi [2] & 20 weeks pregnancy & - & $\begin{array}{l}\text { myomectomy ( } 21 \text { weeks } \\
\text { of gestation) }\end{array}$ & $\begin{array}{c}\text { Anaerobic } \\
\text { Gram-negative rods }\end{array}$ & S \\
\hline Present case, 2013 & 30 days postpartum & uterine fibroids & myomectomy & $\begin{array}{l}\text { Sphingomonas } \\
\text { paucimobilis }\end{array}$ & $S$ \\
\hline
\end{tabular}


pre-menopausal women, in order to preserve their fertility. Myomectomy can even be safely performed during the first and second trimesters of pregnancy, but in all cases the prompt initiation of broad-spectrum antibiotic treatment is critical for good outcome.

Pyomyoma is usually associated with polymicrobial infection [21] by microrganisms such as Clostridium sp, Staphyloccocus sp, Streptococcus sp., Proteus sp, Serratia marcescens, Enterococcus faecalis, Klebsiella pneumoniae, Escherichia coli and Candida sp. This, however is the first report of septicaemia linked to pyomyoma in the puerperal period caused by S. paucimobilis.

S. paucimobilis, a non-fermenting Gram-negative bacillus, is widely distributed in nature and hospital environments. It has been implicated in a variety of human infections, including bacteraemia, pneumonia, catheterrelated infections, meningitis, peritonitis, osteomyelitis, septic arthritis, postoperative endophthalmitis, lung empyema, splenic abscesses, and urinary tract infections [22]. The most common comorbidities included malignancy, immunodeficiency, and diabetes mellitus.

Although sporadic or community-acquired infections have been described, this organism is increasingly associated with nosocomial settings, and hospital-acquired bacteraemia accounts for two-third of reported cases. Nosocomial outbreaks are usually related to manipulation of indwelling devices or contamination of sterile fluids [23], and outbreaks are more likely to occur in dialysis units $[24,25]$, haematology and oncology wards [5,6], and neonatal intensive care units [7].

Kriet et al. reported a case of endogenous postpartum panophthalmitis induced by $S$. paucimobilis in a primiparous 39-year-old with a diagnosis of postpartum endomyometritis [26], presumably contracted in the hospital setting. Likewise, in our case, although there was no clear evidence of nosocomial risk factors, such as previous antimicrobial therapy, invasive procedures, or placement of foreign bodies, and no recent cases of $S$. paucimobilis bacteraemia in our hospital, we cannot rule out bacterial colonization of the hospital water system.

In conclusion, this case highlights a singular manifestation of infection by S. paucimobilis, an opportunistic pathogen emergent in the nosocomial setting. Hence its potential implication in unusual life-threatening infections, such as pyomyoma, should be kept in mind. Furthermore, pyomyoma should be considered in the broad differential diagnosis of postpartum fever, especially if concomitant with bacteraemia and uterine fibroids but no other obvious source of infection. Indeed, this suppurative process is invariably fatal without surgery [27] combined with appropriate antibiotic treatment. Nowadays, however, surgery does not necessarily involve hysterectomy, and potential fertility can be preserved by means of conservative procedures such as myomectomy [19].

\section{Consent}

Written informed consent has been obtained from the patient for publication of this Case report. A copy of the written consent is available for check by the Editor of BMC Infectious Diseases, if needed.

\section{Competing interests}

The authors declare that they have no competing interests.

\section{Authors' contributions}

CDB collected the clinical data and drafted of the manuscript, VB, FM, AV, and ML managed the patient, and supported CDB in the collection of clinical data and drafting of the manuscript, RM and TT performed the literature search and support CDB in the drafting of and revising the manuscript, FM contributed to the clinical and therapeutic management from a gynecologic point-of-view, and revised the gynecologic details of the manuscript, CMM supervised the clinical case interpretation, participated in the coordination and concept of the manuscript, and helped with the draft of the manuscript. All authors read and approved the manuscript.

\section{Acknowledgments}

The authors thank Dr. Paolo Fabietti and Vito Sante Mercurio for their help in the diagnosis and treatment of the patient.

\section{Author details}

${ }^{1}$ Infectious Disease Unit, Fondazione Eleonora Lorillard Spencer Cenci, Sapienza University, Corso Della Repubblica 79, 04100 Latina, Italy. ${ }^{2}$ Obstetrics and Gynecology Unit, SM Goretti Hospital, Latina, Italy.

Received: 12 July 2013 Accepted: 2 December 2013

Published: 5 December 2013

\section{References}

1. Mason TC, Adair J, Lee YC: Postpartum Pyomyoma. J Natl Med Assoc 2005, 97:826-828.

2. Kobayashi F, Kondoh E, Hamanishi J, Kawamura Y, Tatsumi K, Konishi I: Pyomyoma during pregnancy: a case report and review of the literature. J Obstet Gynaecol Res 2013, 39:383-389.

3. Holmes B, Owen RJ, Evans A, Malnick H, Willcox WR: Pseudomonas paucimobilis, a new species isolated from human clinical specimens, the hospital environment, and other sources. Int J Syst Bacteriol 1977, 27:133-146.

4. Tada $Y$, Inoue $T$ : Use of oligotrophic bacteria for the biological monitoring of heavy metals. J Appl Microbiol 2000, 88(1):154-160.

5. Kilic A, Senses Z, Kurekci AE, Aydogan H, Sener K, Kismet E, et al: Nosocomial outbreak of Sphingomonas paucimobilis bacteremia in a hemato/oncology unit. Jpn J Infect Dis 2007, 60:394-396.

6. Perola O, Nousiainen T, Suomalainen S, Aukee S, Karkkainen UM, Kauppinen J, et al: Recurrent Sphingomonas paucimobilis bacteraemia associated with a multi-bacterial water-borne epidemic among neutropenic patients. J Hosp Infect 2002, 50:196-201.

7. Lemaitre D, Elaichouni A, Hundhausen M, Claeys G, Vanhaesebrouck P, Vaneechoutte $M$, et al: Tracheal colonization with Sphingomonas paucimobilis in mechanically ventilated neonates due to contaminated ventilator temperature probes. J Hosp Infect 1996, 32:199-206.

8. Maragakis LL, Chaiwarith R, Srinivasan A, Torriani FJ, Avdic E, Lee A, et al: Sphingomonas paucimobilis bloodstream infections associated with contaminated intravenous fentanyl. Emerg Infect Dis 2009, 15:12-18.

9. Dubois J, Neumann E: Nécrobiose d'un volumineux fibrome trois semaines après un accouchment normal (Necrobiosis of a voluminous fibroma three weeks after a normal labor). Bull Fed Soc Gynecol Obstet Lang Fr 1957, 9:160-161.

10. Ruch WA: Intrapartum rupture of suppurative myoma with purulent peritonitis: report of a case. Obstet Gynecol 1963, 21:593-596.

11. Wong TC, Bard DS, Pearce LW: Unusual case of IUD associated postabortal sepsis complicated by an infected necrotic leiomyoma, suppurative pelvic thrombophlebitis, ovarian vein thrombosis, hemoperitoneum and drug fever. J Ark Med Soc 1986, 83:138-147. 
12. Prichard JG, Lowenstein MH, Silverman IJ, Brennan JC: Streptococcus milleri pyomyoma simulating infective endocarditis. Obstet Gynecol 1986, 68:46S-49S.

13. Tobias DH, Koenigsberg M, Kogan M, Edelman M, LevGur M: Pyomyoma after uterine instrumentation. A case report. J Reprod Med 1996, 41:375-378.

14. Prahlow JA, Cappellari JO, Washburn SA: Uterine pyomyoma as a complication of pregnancy in an intravenous drug user. South Med J 1996, 89:892-895.

15. Grüne B, Zikulnig E, Gembruch U: Sepsis in second trimester of pregnancy due to an infected myoma. A case report and a review of the literature. Fetal Diagn Ther 2001, 16:245-247.

16. Lin $\mathrm{YH}$, Hwang $\mathrm{L}$, Huang LW, Chen HJ: Pyomyoma after a cesarean section. Acta Obstet Gynecol Scand 2002, 81:571-572.

17. Karcaaltincaba M, Sudakoff GS: CT of a ruptured pyomyoma. AJR Am J Roentgenol 2003, 181:1375-1377.

18. Nguyen $\mathrm{QH}$, Gruenewald SM: Sonographic appearance of a postpartum pyomyoma with gas production. J Clin Ultrasound 2008, 36:186-188.

19. Laubach M, Breugelmans M, Leyder M, Demey J, Foulon W: Nonsurgical treatment of pyomyoma in the postpartum period. Surg Infect 2011, 12:65-68.

20. Shaaban HS, Choo HF, Sensakovic JW: A case of Staphylococcus lugdunensis related pyomyoma occurring after cesarean section. J Glob Infect Dis 2011, 3:101-102.

21. Greenspoon JS, Ault M, James BA, Kaplan L: Pyomyoma associated with polymicrobial bacteremia and fatal septic shock: case report and review of the literature. Obstet Gynecol Surv 1990, 45:563-569.

22. Ryan MP, Adley CC: Sphingomonas paucimobilis: a persistent Gram negative nosocomial infectious organism. J Hosp Infect 2010, 75:153-157.

23. Lin JN, Laia $\mathrm{CH}$, Chen $\mathrm{YH}$, et al: Sphingomonas paucimobilis bacteremia in humans: 16 case reports and a literature review. J Microbiol Immunol Infect 2010, 43:35-42.

24. Dervisoglu E, Meric M, Kalender B, Sengul E: Sphingomonas paucimobilis peritonitis: a case report and literature review. Perit Dial Int 2008, 28:547-550.

25. Gomila M, Gascó J, Busquets A, Gil J, Bernabeu R, Buades JM, Lalucat J: Identification of culturable bacteria present in haemodialysis water and fluid. FEMS Microbiol Ecol 2005, 52:101-114.

26. Kriet MM, Bouya Y, Louaya S: Endogenous postpartum panophthalmitis induced by sphingomonas paucimobilis. Bull Soc Belge Ophtalmol 2011, 318:37-40.

27. Zangeneh M, Alsadat Mahdavi A, Amini E, Davar Siadat S, Karimian L: Pyomyoma in a premenopausal woman with fever of unknown origin. Obstet Gynecol 2010, 116:526-528

doi:10.1186/1471-2334-13-574

Cite this article as: Del Borgo et al:: Postpartum fever in the presence of a fibroid: Sphingomonas paucimobilis sepsis associated with pyomyoma. BMC Infectious Diseases 2013 13:574.

\section{Submit your next manuscript to BioMed Central and take full advantage of:}

- Convenient online submission

- Thorough peer review

- No space constraints or color figure charges

- Immediate publication on acceptance

- Inclusion in PubMed, CAS, Scopus and Google Scholar

- Research which is freely available for redistribution

Submit your manuscript at www.biomedcentral.com/submit
Ciomed Central 